\title{
Bloqueio infraclavicular vertical: avaliação da técnica
}

\author{
Hospital Bandeirantes e Hospital Glória, São Paulo
}

- Waldir Cunha Júnior

- Guilherme F. G. Cunha

Marcelo W. M. Hamaji

-Wagner Kuriki
INTRLDUÇÃa

O bloqueio infraclavicular ainda é pouco difundido e utilizado para as anestesias do plexo braquial, principalmente a técnica vertical, devido ao temor das complicações e principalmente pelo desconhecimento da técnica.

MÉTIDOS

Foram avaliados 35 pacientes, P1 e 2 (antigos ASA I e II), com idade entre 15 e 80 anos, submetidos a tratamento cirúrgico de fratura dos ossos do membro superior, terço inferior do úmero até a mão. Foram excluídos os portadores de doenças pulmonares e aqueles cujos pontos de referência fossem de difícil identificação. O bloqueio foi realizado com os pacientes em posição supina, com o membro a ser bloqueado sobre o abdome, facilitando a observação dos movimentos dos músculos quando estimulados. A agulha foi introduzida verticalmente na linha medioclavicular, entre o acrômio e a fossa jugular abaixo da clavícula, a uma profundidade não superior a $4 \mathrm{~cm}$ e com estímulo inicial de $1 \mathrm{~mA}$. Foram considerados estímulos satisfatórios as respostas dos fascículos posterior e medial, com respostas abaixo de $0,35 \mathrm{~mA}$. Nesse local foram injetados $30 \mathrm{ml}$ de solução de ropivacaína $0,5 \%$.

RESULTADDS

O tempo de latência foi em torno de 20 minutos. Houve dois bloqueios incompletos, um na região do cotovelo e outro na região supracondiliana.
DIScUSSÃロ

Nossos resultados estão de acordo com a literatura, não havendo dificuldade na realização dos bloqueios ou complicaçōes.

CロNCLUSÃロ

A técnica é simples, porém a segurança da realização e o êxito parecem estar diretamente relacionados à observação dos pontos de referência. Nos casos em que o local de punção não tem como ser definido, deve-se usar outra técnica de bloqueio.

REFERÊNCIAS

Neuburger M, Kaiser H, Schuster R. Vertical infraclavicular block ofbrachial plexus. Anaesth. 1998;47(7):595-9.

2. Kilka HG, Geiger P. Infraclavicular braquial plexus blockade, a new tecninique of regional anaesthesia. Anaesth. 1995;44(5);339-44.

Endereço para correspondência:

Waldir Cunha Júnior

R. Cayowaá, 560 - apto. 132

São Paulo (SP) - CEP 05018-000

Tel. (+55 11) 9973-7008

E-mail: familiacunha@uol.com.br 